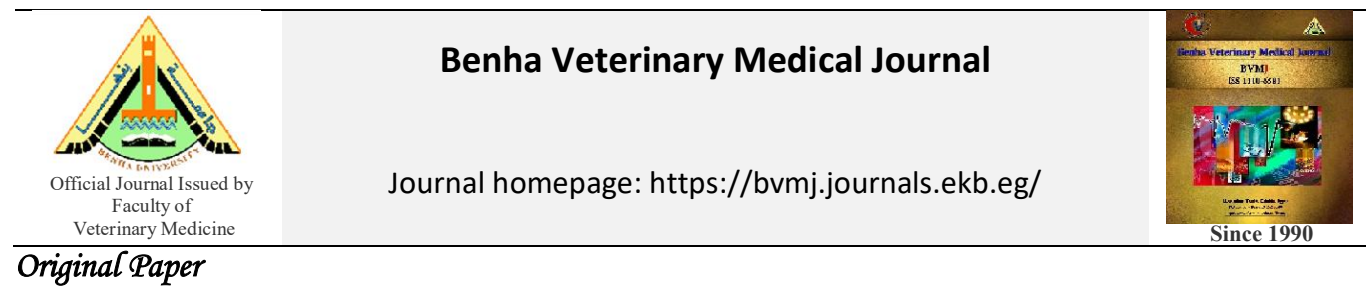

\title{
Efficacy of live attenuated and inactivated bivalent vaccine against canine distemper and canine parvo viruses in dogs
}

Gabr F. Elbagory, Shaimaa Elkhatib, , Mohammad Khodier, Hassan

Department of Virology, Faculty of Veterinary Medicine, Banha University

Veterinary Serum and Vaccine Research Institute (VSVRI), Abbasia, Cairo

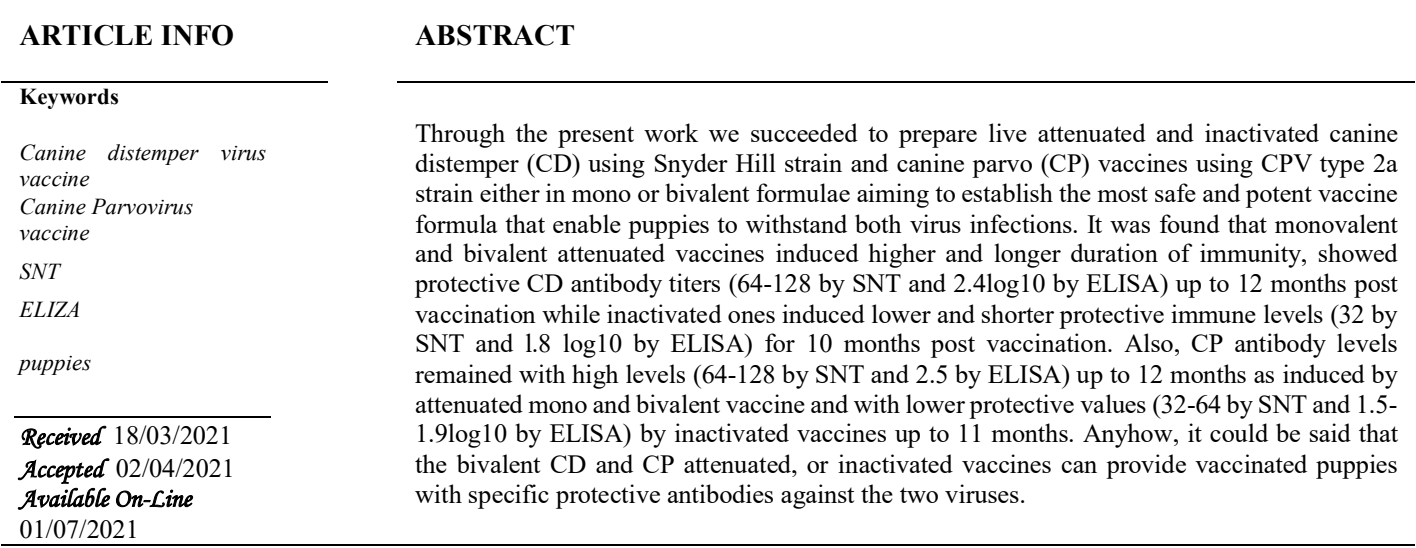

\section{INTRODUCTION}

Canine distemper $(C D)$ is a highly contagious acute or subacute disease caused by a single-stranded RNA virus belonging to the genus Morbillivirus of Paramyxoviridae family (American Veterinary Medical Association, 2016). $\mathrm{CD}$ can cause respiratory, gastroenteritis, and nervous symptoms in different ages of dogs, but young puppies are especially vulnerable. Control of canine distemper virus infection is based on adequate diagnosis, quarantine, sanitation, and vaccination. The virus is very fragile, and susceptible to standard disinfectants. Thorough disinfection of premises, however, can be very challenging. Successful immunization of pups with attenuated canine distemper virus vaccines depends on the absence of interfering maternal antibody. The age at which pups can be immunized can be predicted from a nomograph if the serum antibody titer of the mother is known; this service is available in some diagnostic laboratories. Alternatively, pups can be vaccinated with modified live-virus vaccine at 6 weeks of age and then at 2- to 4-week intervals until 16 weeks of age, which is often now the standard practice (MacLachlan et al,2011). Puppies should start receiving vaccinations at 6-8 weeks of age followed by booster shot every 2-4 weeks until they are 16 weeks old (MAR VISTA Vet, 2012).Canine parvovirus (CP2) is disease causes a severe enteric infection with bloody diarrhea, immune suppression and also high fatality rates. The continuous incidence of enteritis is due to the ability of the virus to mutate, which gives rise to new, more resistant and virulent subspecies (Goddard, 2010).
Attenuated CPV vaccines provided superior protection and immunity for a longer period of time (Spibey et al., 2008). There have been concerns expressed over the efficacy of canine parvovirus vaccines which are based on the original type-2 strain. It has previously been demonstrated that a type- 2 vaccine is able to provide protection against type $2 \mathrm{a}$ and $2 \mathrm{~b}$ field isolates (Martella et al, 2005). Monovalent CPV-2 vaccines are also available, some of them containing very high titer virus (107 TCID50) and widely recommended for initial vaccination of pups (Truyen, 2006) Many effective live and inactivated vaccines have been developed to protect dogs from $\mathrm{CD}$ and $\mathrm{CP}$ virus infections, either in single or bivalent forms (Ackerman et al, 1983; Churchill, 1987 and Bass et al, 1982). In Egypt, single live attenuated $\mathrm{CD}$ and $\mathrm{CP}$ vaccines as well as bivalent live attenuated $\mathrm{CD}$ and $\mathrm{CP}$ vaccines were successfully prepared (Koteb, 1994 and Khodeir et al, 1998). In addition, single inactivated $\mathrm{CP}$ and $\mathrm{CD}$ vaccines were prepared by (Koteb et al, 1998 and Abdalla, 2001) respectively. Furthermore, inactivated trivalent $\mathrm{CD} ; \mathrm{CP}$ and rabies vaccines were prepared and found to be highly potent by (Saleh et al, 2002 and Salama et al, 2003). It was concluded that the inactivated vaccines are more stable and easier to handle under field conditions (Lavender and Bewsey, 1973).

The present work aimed to evaluate the efficacy of locally prepared attenuated and /or inactivated bivalent $\mathrm{CD}$ and $\mathrm{CP}$ vaccines could induce the highest and longest antibody response in vaccinated dogs against $\mathrm{CDV}$ and $\mathrm{CPV}$.

* Corresponding author: shelkhatib90@gmail.com 


\section{MATERIAL AND METHODS}

2.1. Ethical approval:

Care and use of the animals were approved by the Medical and Veterinary Research Ethics Committee at the National Research Centre in Egypt (No., 20/053).

\subsection{Virus strains and cell culture}

2.2.1. Canine distemper virus and canine parvovirus strains: Vero cell culture adapted canine distemper virus Snyder Hill strain (Guirguis, 1991) and MDCK cell culture adapted canine parvovirus type 2a (El-Gendy, 2018) were supplied by Veterinary Serum and Vaccine Research Institute (VSVRI) Abassia Cairo and used in vaccine preparations and SNT and ELIZA.

\subsubsection{Cell culture:}

African green monkey kidney line (Vero) and Madin Darby canine kidney (MDCK) cell lines were supplied by VSVRI and used for propagation of $\mathrm{CD}$ and $\mathrm{CP}$ viruses respectively for vaccine preparations and serum neutralization test.

\subsubsection{Virus propagation in tissue culture:}

Confluent Vero and MDCK cell lines in roller flasks were inoculated with $\mathrm{CD}$ and $\mathrm{CP}$ viruses respectively with MOI 2:1 and when complete CPE of each virus was obtained, such flasks were subjected to two cycles of freezing and thawing and the harvest was aseptically centrifuged for 10 minutes at $3000 \mathrm{rpm}$ in cooling centrifuge. Harvested viruses were tested for sterility and titration.

\subsubsection{Virus titration:}

Tenfold serial dilutions of the virus to be titrated were prepared in Hanks balanced salt solution (10-1 to $10-10$ dilutions) inoculated in the same cell culture used for each virus propagation. The virus titer was expressed as $\log 10$ TCID $50 / \mathrm{ml}$ of the original inoculums using the formula of (Reed and Meunch, 1938).

\subsection{Animals:}

2.3.1. Puppies:

Twenty-one native breed puppies of 3 to 4 months of age free from canine distemper and canine parvovirus antibodies, as screened by serum neutralization test were used in the present study divided into 7 groups (3puppies in each group) for potency test of the prepared monovalent and bivalent $\mathrm{CD}$ and $\mathrm{CP}$ vaccines. In addition, another 12 puppies were used in the safety testing of the prepared vaccine formulae (two puppies for each formula).

\subsubsection{Mice:}

Seventy-two weaned Swiss Albino mice (4weeks old of about 25 gm bodyweights) were supplied by VSVRI and were used for testing the safety of the prepared vaccine formulae.

\subsection{Preparation of inactivated vaccines}

Equal volumes of inactivated $\mathrm{CD}$ and $\mathrm{CP}$ virus fluids containing protective amounts of each virus protein were mixed with $20 \%$ alhydragel as adjuvant to make a bivalent inactivated CD and CP vaccine (Salama et al., 2003). Virus inactivation was performed on $\mathrm{CD}$ and $\mathrm{CP}$ viruses with Binary Ethyleneimine (BEI) working solution $0.01 \mathrm{M}$ prepared according to (Girard et al.,1977). For canine distemper virus inactivation, $3 \%$ of the stock BEI solution was used at $37 \mathrm{o} \mathrm{C}$ for 7 hours and for canine parvovirus inactivation, 5 hours were used (Saleh et al, 2002).
2\% Aluminum hydroxide gel was supplied by Superfos Biosector a/s. Frydenlunds Denmark and used as an adjuvant for the prepared inactivated vaccines at the ratio of $20 \%$.

\subsection{Preparation of attenuated vaccines}

2.5.1. Preparation of monovalent $\mathrm{CD}$ and $\mathrm{CP}$ attenuated vaccines: To prepare monovalent live attenuated vaccines (either $\mathrm{CD}$ or $\mathrm{CP}$ ), stabilizer composed of 5\% lactalbumine hydrolysate and $2.5 \%$ sucrose was added to the titrated and sterility tested virus suspension in the ratio of 1:1 then dispensed in neutral sterile vials $(2.5 \mathrm{ml} / \mathrm{vial})$ and subjected to freeze dry in (lyophilization) process according to (Guirguis, 1991 and kotob, 1994).

2.5.2. Preparation of bivalent live $\mathrm{CD}$ and $\mathrm{CP}$ vaccine: This step was performed through mixing of $C D$ and $C P$ virus suspensions in equal volumes where each $1 \mathrm{ml}$ contains not less than $3 \log 10$ TCID50 of each virus then the stabilizer was added as above, dispensed as $2.5 \mathrm{ml} /$ vial and subjected to freeze drying process according to (Khodeir et al., 1998) The lyophilizing technique was carried out on Teflon lyophilize apparatus (Wang and Zhang, 2007).

\subsection{Sterility test:}

Using thioglycolate, soyabean casein digest, Sabouraud, and mycoplasma solid and liquid media, sterility testing of the prepared vaccines was performed according to standard procedures (FAO, 1994).

\subsection{Safety test:}

2.7.1. In mice:

Five vials of each vaccine were pooled and $0.03 \mathrm{ml}$ of each vaccine was inoculated intra peritoneal in each of eight weaned Swiss Albino mice, according to the (WHO, 1973). For ten days, inoculated mice were kept under observation alongside eight non-inoculated mice.

\subsubsection{In puppies:}

According to the protocol, two puppies were inoculated S/C with ten doses of each vaccine and kept under daily clinical observation for ten days (Saleh et al., 2002).

\subsection{Vaccination protocol}

The potency of live attenuated vaccines was tested through vaccination of puppy's groups 1,2 and 3 with single $C D$, single $\mathrm{CP}$ and bivalent $\mathrm{CD}$ and $\mathrm{CP}$ vaccines respectively. Each puppy received one dose inoculated $\mathrm{S} / \mathrm{C}$ including $3 \log 10$ TCID50 of each virus according to (Khodeir et al., 1998). On the other hand, the potency of monovalent CD, $\mathrm{CP}$ and bivalent $\mathrm{CD}$ and $\mathrm{CP}$ inactivated vaccines was tested in puppy groups 4, 5 and 6 respectively. Each puppy was inoculated $\mathrm{S} / \mathrm{C}$ with $1 \mathrm{ml}$ of the used vaccine according to (Saleh et al., 2002). Puppy group-7 was kept without vaccination as negative control. Serum samples were obtained from all puppies on week intervals up to 4 weeks post vaccination then on monthly intervals up to 12 months later for monitoring of induced antibodies using serum neutralization test.

\subsection{Serum neutralization test (SNT):}

SNT was carried out in Vero and MDCK cell cultures for $\mathrm{CD}$ and $\mathrm{CP}$ respectively micro technique method as described by (Ferreira, 1976). Twofold dilutions of inactivated sera were mixed with equal volumes of the used virus suspension containing 100 TCID50. Virus and serum mixtures were assayed in cell cultures using 2 wells per dilution. Infected cultures and normal controls were incubated kept at $37^{\circ} \mathrm{C}$ with daily microscopic examination. 
The end point of neutralizing antibody titers was expressed as the reciprocal of the final dilution of serum inhibiting the CPE according to (Singh et al.,1967).

\subsection{Indirect ELISA:}

According to the bombinated methods of (Hubschle et al.,1981 and Voller et al., 1976) indirect ELISA was carried out for monitoring immune response for $\mathrm{CD}$ and $\mathrm{CP}$ induced in vaccinated puppies using anti-dog immunoglobulin [IgG whole molecule conjugated with Horse Radish Peroxidase (HRP)] obtained from Sigma Chemical Company (USA).

\section{RESULTS}

The present obtained results revealed that all prepared monovalent and bivalent live and inactivated $\mathrm{CD}$ and $\mathrm{CP}$ vaccines were found to be free from aerobic and anaerobic bacteria, fungi and mycoplasma. Also, all of these vaccines did not induce any abnormal local or systemic post inoculation reactions neither in mice nor in puppies.

Table 1 Mean CD serum neutralizing antibody titers in vaccinated 18 puppies with monovalent attenuated and inactivated CD vaccine and bivalent attenuated and inactivated $\mathrm{CD}$ and $\mathrm{CP}$ vaccine.

\begin{tabular}{|c|c|c|c|c|c|c|}
\hline \multirow{3}{*}{ Period post vaccination } & \multicolumn{2}{|c|}{ Mean CD serum neutralizing antibody titer * induced by } & \multirow{3}{*}{ Single inactivated $\mathrm{CD}$} & \multirow{3}{*}{$\begin{array}{l}\text { Bivalent } \\
\text { CD\&CP }\end{array}$} & \multirow{3}{*}{ inactivated } & \multirow{3}{*}{ Non-vaccinated puppies } \\
\hline & Single live CD & Bivalent live $\mathrm{CD} \& \mathrm{CP}$ & & & & \\
\hline & & & & & & \\
\hline Zero time & 0 & 0 & 0 & & 0 & 0 \\
\hline $1 \mathrm{WPV}^{* *}$ & 8 & 4 & 2 & & $2 \leq$ & 0 \\
\hline $2 \mathrm{WPV}$ & 16 & 8 & 4 & & 2 & 0 \\
\hline $3 W P V$ & 32 & 32 & 8 & & 4 & 0 \\
\hline 4WPV & 64 & 64 & 16 & & 16 & 0 \\
\hline $2 \mathrm{MPV}^{* * *}$ & 128 & 128 & 32 & & 32 & 0 \\
\hline $3 \mathrm{MPV}$ & 128 & 128 & 64 & & 64 & 0 \\
\hline $4 \mathrm{MPV}$ & 128 & 128 & 64 & & 64 & 0 \\
\hline $5 \mathrm{MPV}$ & 128 & 128 & 64 & & 64 & 0 \\
\hline $6 \mathrm{MPV}$ & 128 & 128 & 64 & & 64 & 0 \\
\hline $7 \mathrm{MPV}$ & 128 & 128 & 64 & & 64 & 0 \\
\hline $8 \mathrm{MPV}$ & 128 & 128 & 64 & & 64 & 0 \\
\hline $9 \mathrm{MPV}$ & 128 & 128 & 64 & & 64 & 0 \\
\hline $10 \mathrm{MPV}$ & 128 & 128 & 32 & & 32 & 0 \\
\hline $11 \mathrm{MPV}$ & 128 & 128 & 16 & & 16 & 0 \\
\hline $12 \mathrm{MPV}$ & 128 & 64 & 8 & & 4 & 0 \\
\hline
\end{tabular}

$* \mathrm{CD}$ serum neutralizing antibody titer $=$ the reciprocal of the final serum dilution which neutralized and inhibited the CPE of $100 \mathrm{TCID} 50$ of $\mathrm{CD}$ virus $* * \mathrm{WPV}=$ weeks post vaccination $\quad * * * \mathrm{MPV}=$ months post vaccination

Table 2 Mean CD ELISA antibody titers in vaccinated 18 puppies monovalent attenuated and inactivated CD vaccine and bivalent attenuated and inactivated CD and $\mathrm{CP}$ vaccine

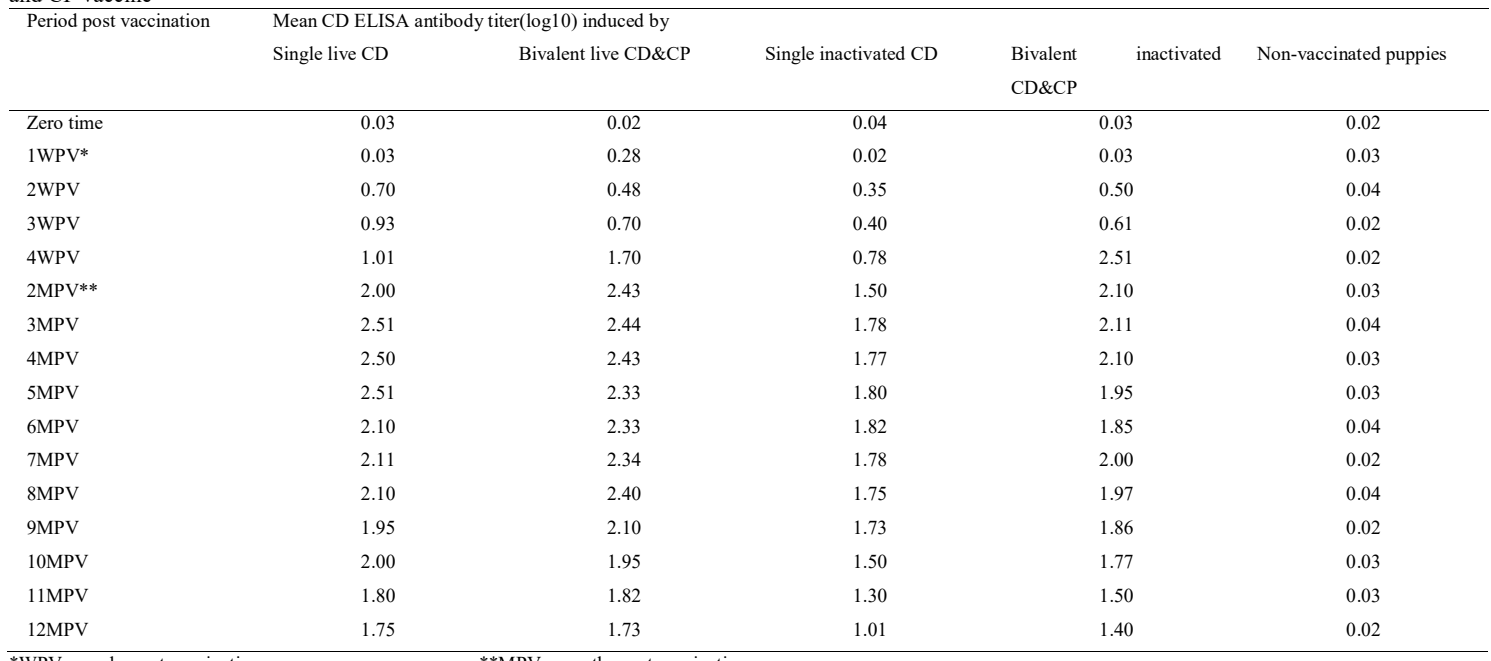

*WPV= weeks post vaccination $\quad$ **MPV= months post vaccination

*ELISA antibody titer is measured using special formula using Sample/ positive ratio(SP) ratio for each sample and this formula differs according to each virus. 


\begin{tabular}{|c|c|c|c|c|c|c|}
\hline \multirow[t]{3}{*}{ Period post vaccination } & \multicolumn{6}{|c|}{ Mean CP serum neutralizing antibody titer * induced by } \\
\hline & Single live CP & Bivalent live $\mathrm{CD} \& \mathrm{CP}$ & Single inactivated $\mathrm{CP}$ & Bivalent & inactivated & Non-vaccinated puppies \\
\hline & & & & $\mathrm{CD} \& \mathrm{CP}$ & & \\
\hline Zero time & 0 & 0 & 0 & & 0 & 0 \\
\hline $1 \mathrm{WPV} * *$ & 4 & 2 & $2 \leq$ & & $2 \leq$ & 0 \\
\hline 2WPV & 8 & 4 & 2 & & 2 & 0 \\
\hline $3 \mathrm{WPV}$ & 16 & 16 & 4 & & 8 & 0 \\
\hline $4 \mathrm{WPV}$ & 64 & 32 & 16 & & 16 & 0 \\
\hline $2 \mathrm{MPV} * * *$ & 128 & 128 & 32 & & 32 & 0 \\
\hline $3 \mathrm{MPV}$ & 128 & 128 & 64 & & 64 & 0 \\
\hline 4MPV & 128 & 128 & 64 & & 64 & 0 \\
\hline $5 \mathrm{MPV}$ & 128 & 128 & 64 & & 64 & 0 \\
\hline $6 \mathrm{MPV}$ & 128 & 128 & 64 & & 64 & 0 \\
\hline $7 \mathrm{MPV}$ & 128 & 128 & 64 & & 64 & 0 \\
\hline 8MPV & 128 & 128 & 32 & & 64 & 0 \\
\hline $9 \mathrm{MPV}$ & 128 & 128 & 32 & & 32 & 0 \\
\hline $10 \mathrm{MPV}$ & 128 & 128 & 16 & & 16 & 0 \\
\hline $11 \mathrm{MPV}$ & 128 & 128 & 8 & & 16 & 0 \\
\hline $12 \mathrm{MPV}$ & 128 & 128 & 4 & & 8 & 0 \\
\hline
\end{tabular}

128

*CP serum neutralizing antibody titer= the reciprocal of the final serum dilution which neutralized and inhibited the $\mathrm{CPE}$ of $100 \mathrm{TCID}_{50}$ of $\mathrm{CP}$ virus
${ }^{* *} \mathrm{WPV}=$ weeks post vaccination $* * \mathrm{WPV}=$ weeks post vaccination

\begin{tabular}{|c|c|c|c|c|c|c|}
\hline \multirow[t]{3}{*}{ Period post vaccination } & \multicolumn{2}{|c|}{ Mean CP ELISA antibody titer $(\log 10)$ induced by } & \multirow{3}{*}{ Single inactivated $\mathrm{CP}$} & \multirow{3}{*}{$\begin{array}{l}\text { Bivalent } \\
\text { CD\&CP }\end{array}$} & \multirow{3}{*}{ inactivated } & \multirow{3}{*}{ Non-vaccinated puppies } \\
\hline & Single live $\mathrm{CP}$ & Bivalent live $\mathrm{CD} \& \mathrm{CP}$ & & & & \\
\hline & & & & & & \\
\hline Zero time & 0.03 & 0.02 & 0.04 & & 0.03 & 0.04 \\
\hline $1 \mathrm{WPV} *$ & 0.90 & 0.68 & 0.59 & & 0.68 & 0.02 \\
\hline $2 \mathrm{WPV}$ & 1.33 & 1.08 & 1.00 & & 1.08 & 0.03 \\
\hline $3 \mathrm{WPV}$ & 1.95 & 1.51 & 1.95 & & 1.51 & 0.02 \\
\hline $4 \mathrm{WPV}$ & 2.23 & 1.91 & 2.23 & & 1.91 & 0.03 \\
\hline $2 \mathrm{MPV}^{* *}$ & 2.51 & 2.33 & 2.55 & & 2.33 & 0.04 \\
\hline $3 \mathrm{MPV}$ & 2.36 & 2.35 & 2.60 & & 2.50 & 0.03 \\
\hline $4 \mathrm{MPV}$ & 2.50 & 2.45 & 2.54 & & 2.55 & 0.03 \\
\hline $5 \mathrm{MPV}$ & 2.46 & 2.50 & 2.55 & & 2.55 & 0.04 \\
\hline $6 \mathrm{MPV}$ & 2.45 & 2.45 & 2.50 & & 2.46 & 0.02 \\
\hline $7 \mathrm{MPV}$ & 2.40 & 2.35 & 2.45 & & 2.50 & 0.04 \\
\hline $8 \mathrm{MPV}$ & 2.11 & 2.10 & 2.33 & & 2.44 & 0.02 \\
\hline $9 \mathrm{MPV}$ & 1.90 & 2.00 & 1.90 & & 1.90 & 0.04 \\
\hline $10 \mathrm{MPV}$ & 1.85 & 1.95 & 1.75 & & 0.85 & 0.03 \\
\hline $11 \mathrm{MPV}$ & 1.77 & 1.80 & 1.50 & & 1.51 & 0.03 \\
\hline $12 \mathrm{MPV}$ & 1.75 & 1.77 & 0.75 & & 0.62 & 0.04 \\
\hline
\end{tabular}

\section{DISCUSSION}

$\mathrm{CD}$ and $\mathrm{CP}$ vaccines are corner stones in the control of $\mathrm{CD}$ and $\mathrm{CP}$ virus infections which represent the most dangerous viral diseases affecting dog population in dramatic forms resulting in huge economic losses especially among high dog breeds. Production of local vaccines safe high costs of importation and aid to control the diseases in local breeds. The obtained results showed that all prepared $\mathrm{CD}$ and $\mathrm{CP}$ vaccines were found to be free from foreign contaminants (aerobic and anaerobic bacteria, fungi and mycoplasma) and safe where there were no serious adverse reactions in any mice and puppies showing no post inoculation abnormal local or systemic signs as what recommended by (WHO,1973).

All puppies in all groups responded well to the CPV and CDV components of the prepared attenuated and inactivated single and bivalent vaccines as determined by SNT and ELIZA.

The immune responses of vaccinated dogs to the CDV fractions of both vaccines were considered satisfactory and developed VN titers of 32 or above against CDV on the 3rd week of vaccination by the single and bivalent vaccines recorded peak titers (128) by the 2 nd month later. ELISA titers were 0.93 and $0.70 \log 10$ by the 3 rd week in case of dog vaccination with single and bivalent attenuated vaccine reached their peaks $(2.50$ and $2.43 \log 10)$ by the 3 rd month later. Inactivated single and bivalent vaccines recorded SN antibody titers 32 by the 2 nd month with peak titer (64) by the $3 \mathrm{rd}$ month post vaccination with ELISA titers of 0.40 and $0.61 \log 10$ and 1.80 and $1.95 \log 10$ on the same periods post vaccination respectively. These titers have been considered to be protective (Olson et al, 1988 and Coyne et al,2001). Also, these results agree with the findings of earlier studies in which a 100 per cent response was observed at nine weeks of age and 10 weeks of age (Bergman and Stahl, 1997). These levels of antibodies protected animals against challenge with virulent viruses and came in agreement with (CFR, 1997) that recommended serum neutralizing titer not less than 1:50 (1.7 $\log 10)$ for the $\mathrm{CD}$. The obtained results also agreed with (Guirguis, 1991; Miyamoto et al., 1995; and Khodier et al., 1998) who reported that dogs were considered immune to canine distemper if their antibody titer was higher than 30 .

Regarding the immune response of vaccinated puppies against $\mathrm{CP}$, the results of SNT and ELISA revealed that single and bivalent vaccines induced protective $\mathrm{CP}$ antibody 
titers by 4 th week post vaccination ( $64 \& 32$ by SNT and 1.95 and $1.51 \log 10$ by ELISA respectively) reaching their peaks ( 128 by SNT and $2.5 \log 10$ by ELISA respectively) on the 2nd months and still constant up to 12 months later. Inactivated single and bivalent vaccines showed lower protective CP antibody titers ( 32 by SNT and 1.95 and 1.51 $\log 10$ by ELISA respectively) by the second month with peak titers (64 by SNT and 2.60 and 2.50 by ELISA respectively) by the third month then began to decrease recorded protective CP antibody titers ( 8 by SNT and 1.50 and $1.45 \log 10$ by ELISA respectively) on the 11 th month. These levels of CP antibodies appear to be higher than the recommended protective levels where titer of 8 is protective against clinical disease and intestinal replication of virulent virus as mentioned by (Ackermann et al., 1983) on the other side, (Fiscus et al., 1985) consider neutralizing titer of 16 is protective. In addition, similar findings and recommendations were obtained by (Khodier et al., 1998; Koteb et al., 1998; Saleh et al., 2002 and Koteb and Douad, 2004).

As a result of the safety of inactivated vaccines, as well as their ease of administration at any age, they have become the vaccine of choice, according to the findings. (Olson et al., 1988; Cooper et al., 1995 and Miyamoto et al., 1995).

In accordance with the Animal Welfare Organization and to prevent the spread of virus infections, we did not conduct challenge tests against virulent virus strains during the current study's potency testing of the prepared attenuated and inactivated singleand bivalent $\mathrm{CD}$ and $\mathrm{CP}$ vaccines.

\section{CONCLUSION}

Depending on the present obtained results, it is clear that the bivalent $\mathrm{CD}$ and $\mathrm{CP}$ attenuated, or inactivated vaccines are able to provide puppies with protective antibodies.

\section{REFERENCES}

1. Abdalla, N.I.A. (2001): Studies on the preparation of an inactivated canine distemper vaccine, Ph. D. Vet. Sci. Thesis (Virology), Fac. Vet. Med. Cairo Univ.

2. Ackerman, O.; Stegman, H. and Jaeger, O. (1983): Simultaneous immunization of dogs against parvovirus; distemper; rabies; contagious hepatitis and leptospirosis; Blauen Hefte Furdentierazt, 67: 302-308

3. Aly, N. I; Salama, Z. T. (2005): Preparation of an inactivated penta cell culture vaccine against canine distemper, canine parvo, canine hepatitis "canine adeno-1", canine adeno-2 and rabies viruses for dogs; Beni-Suef Vet Med J (2005) Vol. 15, No. 2, 208-214

4. American Veterinary Medical Association (2016): Canine distemper.

https://www.avma.org/public/PetCare/Pages/CanineDistemper.aspx

5. Bass, E. P.; Gill, M. A. and Beckenhaur, W. H. (1982): Development of a modified live canine origin parvo virus vaccine J.A.V.M.A., 181 (9): 909-913.

6. Bergman, J. G. H. E. \& Stahl, M. (1997): A comparative study with the distemper component of two commercially available vaccines. Proceedings of the 21st Annual Congress of the World Small Animal Veterinary Association. Jerusalem, Israel, October 20 to 23, 1996. p 414

7. CFR (1997): Code American Federal Regulation. Evaluation of pet animal vaccine. 9CFR. pp.598-601.

8. Cooper, P. E.; Chappuis, G.; Saint, G.A. and Duret, C. (1995): Comparison of monovalent and polyvalent vaccines in dogs against canine adeno- and parvovirus infections and rabies. Med. Vet. 12: (5) 341-347.

9. Coyne, M. J., Burr, J. H. H., Yule, T. D., Harding, M. J., Tresnan, D. B. \& Mcgavin, D. (2001): Duration of immunity in dogs after vaccination or naturally acquired infection. Veterinary Record 149, 509-515

10. Churchill, A. E. (1987): Preliminary development of a live attenuated canine parvovirus vaccine from an isolate of British origin, Vet. Rec. 120: 334- 339

11. El-Gendy, I.A.M (2018): Isolation and molecular characterization of canine parvovirus from Cairo and Giza in the period of 2014-2015; M. Vet. Sci. Thesis (Virology) Fac. Vet. Med. Cairo Univ.

12. FAO (1994): Quality control of rinderpest cell culture vaccine; Standard Operating Procedures, FAO report No.118.

13. Ferreira, M.E. (1976): Prubada microneutralization proesludaes de anticurpos de la fiebre aftosa blin centro, Panoamericana de ubrea Akrosa, 211: 17 - 24.

14. Fiscus, S. A.; Mildbrand, M. M.; Gordonf, C. and Scott, W. (1985): Rapid enzyme linked immunosorbent assay for detecting antibodies to canine parvovirus. Am. J.Vet. Res., 46 (4): 859-863.

15. Girard, H.C.; Bayramoglu,O.; Erol.,N. and Burgut, A. (1977): "Inactivation of (O1) FMD virus by binary ethylenemine (BEI)"; Bull. Off. Int. Epiz. 87(3-4): 201217.

16. Guirguis W. I. (1991): Trials for preparation of a vaccine against canine distemper; $\mathrm{Ph}$. D. Thesis (Microbiology) Fac. Vet. Med. Cairo Univ.

17. Goddard, A., \& Leisewitz, A. L. (2010): Canine Parvovirus. Veterinary Clinics of North America: Small Animal Practice, 40(6), 1041-1053.

18. Hubschle, O.J.; Lorenz, R.J. and Mathek, H.D. (1981): Enzyme linked immunosorbent assay for detection of blue tongue virus antigen; Am. J. Vet. Res., 42: 61-65.

19. Lavender J.F. and Bewsey B.J. (1973): Immunogenicity of canine distemper virus vaccine produced in continuous cell line (LLC-MK2 cells), Amer. J.Virol. Res. 34 (9): 1189-1194

20. Khodeir M. H.; Kotb, A.M.; Guirguis W. I. and Habashi Y. Z. (1998): Preparation of a bivalent vaccine against canine distemper and canine parvo viruses; 4thVet Med. Zag. Cong. 152-160

21. Koteb, A. M.; Zaki, H. Y. and Sami, S. M. (1998): Studies on production of an inactivated canine parvovirus vaccine. 4th Vet. Med. Zag. Cong. Egypt. 240-247.

22. Kotb, A, M 1994 (1994): Studies on preparation of canine parvo vaccine; Ph. D. Thesis (Microbiology) Fac. Vet. Med. Cairo Univ.

23. Koteb, A.M and A. M. Douad (2004): Tetravalent dog vaccine (A vaccine against canine distemper, canine parvo, canine hepatitis and rabies). The 1st Int. Conf. Vet. Res. Div., NRC, Cairo, Egypt. pp.74-85.

24. MAR VISTAVet (2012): Canine Distemper: Prevention of Infections; The Merck Veterinary Manual (online): Archived from the original on 2012-04-21.

25. MacLachlan, N.J. and Dubovi, E.J. (2011): Canine Distemper Viruse. Fenner's Veterinary virololgy $4^{\text {th }} \mathrm{ed}$. Elsevier,317-319.

26. Martella V.; Cavalli A.; Decaro N.; Elia G.; Campolo G.; Bozzo, E. and Buonavogila C. (2005): Immunogenicity of an intranasal administrated modified live canine parvovirus type $2 \mathrm{~b}$ vaccine in pups with maternally derived antibodies Clinical and Diagnostic Laboratory Immunology, 12: 1243-1245 
27. Miyamoto, T.; Taura, Y.; Une, S.; Yoshitaka, M. Nakama and Watanobe, S. (1995): Immunological response to polyvalent canine vaccines to dogs. J. Vet. Med. Sci., 57 (2): 347

28. Olson, P., Klingeborn, B. and Headhammer, A. (1988): Serum antibody response to canine parvovirus, canine adenovirus 1, and canine distemper virus in dogs with known status of immunization: Study of dogs in Sweden. American Journal of Veterinary Research 49, 1460-14

29. Reed, L.J. and Muench, H. (1938): A simple method for estimating fifty percent $(50 \%)$ end points; Amer. J. Hyg., 27: 493-497.

30. Saleh, A.A; El-Gallad, S.B.; Khodeir, M.H. and Azab, A.M. (2002): Trivalent inactivated vaccine for dogs (Rabies, Canine Distemper and Canine Parvo); J. Egypt Vet. Med. Ass. 62, No.2: 209-222

31. Saleh, A. A.; El-Galad, S. B.; Khodier, M. K. and Azab, A. M. (2002): Trivalent inactivated vaccine for dogs (rabies, canine distemper and canine parvo). J. Egypt. Vet. Med. Assoc., 62, (2): 209-222.

32. Salama, Z.T.S; Ali, N.I; Guirguis, W.I. and Khodeir, M.H. (2003): Modification of the inactivated trivalent vaccine (Rabies; canine distemper and canine parvo) used for dogs to improve its immunogenicity; J. Egypt Vet. Med. Ass. 63, No.2: 137-146

33. Singh, K.V.; Osman, O.A.; Baz,T.I and El-Cicy and Ivon, El-Cicy(1967): Colostral transfer of rinderpest neutralizing antibodies to offspring of vaccinated dams Can.J.Comp.Med.Vet.Sci.,31: 295-298.

34. Spibey, N.; Greenwood, N.M.; Sutton, D.; Chalmers, W.S. and Tarpey, I. (2008): Canine parvovirus type 2 vaccine protects against virulent challenge with type $2 \mathrm{c}$ virus; Vet. Microbiol. 128: 48-55

35. Truyen, U. (2006): Evaluation of canine parvovirus- a need for new vaccines Vet. Microbiol. 117: 9-13

36. Voller, A.; Bidwell, D. E. and AnnBartlett (1976): Enzyme immuno- assay in diagnostic medicine, theory and practice; Bull. World Health Organ, Vol. 53: 55-65.

37. Wang, J. and Zhang, H (2007): The influence of onestep $-80{ }^{\circ} \mathrm{C}$ cryopreservation on the osteogenesis differentiation ability of human bone marrow-derived mesenchymal stem cells, Guangdong Med.,28(3):365367.

38. WHO (1973): Expert committee on biological standardization; requirements of rabies vaccine for human use, Tech. Rep. Ser., 658: 54-130. 